\title{
Intellectual Impact of Mobile Educational Games on Secondary School Education in Nigeria: Case Study of Government Girls' College Makurdi
}

\author{
Yugh Sandra Mlumun ${ }^{1}$, Deborah Uzoamaka Ebem ${ }^{1}$, Onyianta John Chiedozie ${ }^{1, ~ *}$, \\ Musa Ibrahim Umar', Arinze Uchechukwu Christian ${ }^{3}$ \\ ${ }^{1}$ Department of Computer Science, University of Nigeria, Nsukka, Nigeria \\ ${ }^{2}$ Department of Extension/Management, College of Agriculture, Jalingo, Nigeria \\ ${ }^{3}$ School of Postgraduate Studies (SPGS), Faculty of Physical Sciences, Department of Computer Science, University of Nigeria, Nsukka, \\ Nigeria
}

\section{Email address:}

sandra.yugh.77190@unn.edu.ng (Y. S. Mlumun), deborah.ebem@unn.edu.ng (D. U. Ebem), jonnyspencer210@gmail.com (O. J. Chiedozie), musa.umar.pg76718@unn.edu.ng (M. I. Umar), arinzeuchechukwu@gmail.com (A. U. Christian)

${ }^{*}$ Corresponding author

\section{To cite this article:}

Yugh Sandra Mlumun, Deborah Uzoamaka Ebem, Onyianta John Chiedozie, Musa Ibrahim Umar, Arinze Uchechukwu Christian. Intellectual Impact of Mobile Educational Games on Secondary School Education in Nigeria: Case Study of Government Girls' College Makurdi. American Journal of Information Science and Technology. Vol. 5, No. 3, 2021, pp. 48-59. doi: 10.11648/j.ajist.20210503.11

Received: January 22, 2021; Accepted: April 28, 2021; Published: July 9, 2021

\begin{abstract}
Mobile phones, laptops, tablets and lots more have become a learning tool with unlimited prospects in both classrooms and outdoor learning. Using mobile games in education combines conventional and active learning with fun in possibly exceptional forms. This study accessed the intellectual impact of mobile educational games on secondary school education in Nigeria. A case study approach was adopted for the quantitative research. The sample consisted of 169 students and 52 teachers respectively. Questionnaires were administered to them. Sixty-four percent (64\%) of students and fifty two percent $(52 \%)$ of teachers were aware of mobile educational games. Forty three $(43 \%)$ of students and forty six percent $(46 \%)$ of teachers used mobile educational games. Fifty four (54\%) of students and forty two percent (42\%) of teachers responded that Mobile educational games assist learning and teaching. Forty five (45\%) of students and thirty five (35\%) of teachers responded that existing mobile educational games are very helpful in assisting learning and teaching. Fifty seven percent (57\%) of students and twenty three (23\%) of teachers indicated that existing mobile educational games are not based on secondary school subjects. The study recommended that selected questions for such games should be based on the Nigerian secondaryschool curriculum, and students and teachers should be effectively exposed to this tool so as to enhance the quality of education in the secondary school sector.
\end{abstract}

Keywords: Educational Games, Game-Based Learning (GBL), Play, Mobile Games, Mobil Learning, Teaching

\section{Introduction}

Nigeria has been projected as a knowledge-based and an internationally society whose mission is to fully integrate information and communication technologies into the socioeconomic development and transformation of Nigeria into a knowledge-based economy by the Nigeria National Information Communication Technology [1]. And to help actualize this vision, effective ICT-based teaching and learning in our educational institutions would help [2]. This rapidly changing technology would enable serious thinking and problem-solving in education when its limitless offer to education is understood. Educational games are defined as games premeditated for teaching and learning purposes [3]. Games are activities which possess the following characteristics fun, constrained to place and time, unknown outcome, does not necessarily accomplish useful things, directed by rules and not real [3]. Studies abound on the use of games as educational tools [4-12]. 
In the last decades, emergent attention has heightened regarding the awareness of how computer, videogames and game-like simulations can be beneficial to learning experiences [13-15]. The usage of games as emphasized by [16] in keeping people of diverse learning conditions engrossed in the task for a very long duration of time. Games reflect the way the human mind was designed to learn [17]. Educational games are defined as games which are made up of content of a curriculum or other educational constituents. Mobile games are defined as games that are played using mobile devices such as smart phones, Personal Digital Assistants (PDA), smart watches, portable media players or graphic calculators [18].

Mobile learning and educational gaming are two trends that are rapidly having an increasing impact on TechnologyEnhanced Learning (TEL). Mobile learning (m-learning) has been seen as been evolved from e-learning. Unlike computerbased learning (learning at a specific place with desktop computers), m-learning provides learning/teaching materials to a range of lightweight devices such as, tablets, mobile phones (smartphones) which assist the user for easy learning. This speedy growth of mobile learning is inclined to the capability to access learning content anytime and anywhere [19].

The demand capability is at a higher rate because mobile devices allow for merging of internet and communications technologies. With the accessibility of engines, the growth of mobile applications is faster and seamless [20].

This educational tool has become the mainstream which teachers and parents have recognized and if used by students it could aid valuable skill enhancement like strategic thinking, planning, communication, application of numbers, transferring skills, group decision-making and data-handling [20]. The experience of gameplay considerably seems to affect learners' prospects of learning activities [6]. In a gamebased learning environment, students learn as they play the games. "Preferred" tasks are speedy, sprightly and empirical, with information supplied in multiple forms in side by side of which such demands may not be met by the traditional school-based learning [6].

This research work studied the awareness, accessibility, and effects of using mobile educational games as a means of learning even outside the classroom environment using Government Girls' Secondary School Makurdi, Nigeria. The paper is divided into introduction, the objective of the study, research questions, and review of related literature, methodology, result, and analysis of the result, discussion and conclusion.

\section{Objective of the Study}

The objective of the study was to investigate how informed are the users, how accessible are the games, how effective are the games and the level of satisfaction in the utilization of existing mobile educational learning/teaching games among secondary school students in Nigeria.

\section{Research Questions}

The research questions for this study are:

1. Are secondary school students and teachers aware of existing mobile educational games?

2. Have they used any of the existing mobile educational games?

3. Are the existing mobile educational games tailored to improve students' academic performance?

4. How beneficial are the existing mobile educational games to learning and teaching in secondary schools in Nigeria?

5. Are selected questions for the existing mobile educational games based on subjects taught secondary schools in Nigerian?

\section{Review of Related Literature}

Mobile technology has led to most people carrying their own mobile devices. The large computing powers and portability combined with wireless communication and content-sensitive tools make one-to-one computing a learning tool of great potential in both traditional classroom and outdoor informal learning [21]. A meta-analysis and research synthesis of how effective is the integration of mobile devices in teaching and learning was carried out by [21]. They coded and analyzed 110 experiment and quasiexperimental journal articles published between 1993-2013. In total, there was a moderate mean effect size of 0.523 for the application of mobile devices to education. They also analyzed the effect sizes of the moderator variables together with the advantages and disadvantages of mobile learning of the individual studies.

The awareness of using games in keeping students in the process of active learning is not new. Over the years, educators have been progressively incorporating various games into their teaching curriculum as a means of creating entertaining and engaging learning environment for students [22]. Options to incorporate technology and interactivity to learning process was suggested by Quinn and Iverson as they were quoted to have argued that students "need to be engaged more and to be put at the center of the learning experience to change from 'passive vessel' to 'active participant" as cited by [23] in [22]. In their classroom, they used several games with their students to review earlier taught materials and to prepare them for tests.

They noticed that most of their students tended to enjoy hands-on activities in the courses; however, he sometimes wondered if the students understood the content of the material in the process. According to what he observed, some students appeared to learn more when they are competing in a game or activity while others seemed to be bored or possibly distracted. In the end, the feedback received from students regarding the benefits of the review games which they played was positive and many students suggested that they play them more often. Additionally, in a more general approach, they tried to find information that supports the question: What makes an educational game effective in the 
classroom? Almost seventy percent of students admitted that they learned best actively and visually" as stated by [24] in [22]. Due to that reason, they felt that games have many prospective benefits of active learning in the classroom.

The subject of mobile learning for educational purposes was introduced in a document prepared by [25]. It examined what impact mobile devices have had on teaching and learning practices and go on to look at the opportunities the use of digital media and mobile devices offers. The main purpose of the paper was to describe the current state of mobile learning, benefits, challenges and its barrier to supporting teaching and learning. Data for the study was collected through bibliographic and Internet research from January to March 2013 which covered four (4) areas; 1). Analysis of Mobile learning 2). Differentiating E-learning from Mobile Learning 3). Value and Benefits of Mobile Learning 4). Challenges and Barriers to Mobile Learning.

Possibilities of using mobile learning in schools were demonstrated using the Bulgarian Preschool education of young children [26].

These authors presented and discussed the state of preschool education. The problem concerning the safety of the children when using mobile devices in terms of access to information on the Internet was revealed and analyzed. They designed two conceptual Models of applications of mobile learning aimed at preschool children and their advantages and disadvantages were drawn and discussed.

The Models include;

i). A Conceptual Model of a mobile application for individual learning which supports a parent and a child, where parents are able to monitor the full diary of the child when working with the application.

ii). Mobile application for collecting learning whose idea of design is based on collective learning which involves students, teachers, and parents. The teachers and parents do the setting of a task, the teacher can assess the results achieved by children while parents can only view the assessment but cannot change it. The children could utilize resources such as information, task and view their grade. The advantage of this model is that it enabled parents to actively participate in the education of their children while the disadvantage of the model is the complexity of software development.

To investigate the impact of flow, engagement and immersion on learning in game-based learning environments, Hamari et al., in [27] carried out a study. They gathered through a survey from players $(\mathrm{N}=173)$ of two learning (Quantum Spectre: $\mathrm{N}=134$ and Spumone: $\mathrm{N}=40$ ). The results showed that engagement in the game had a clear positive effect on learning. Conversely, a significant effect between immersion in the game and learning could not be found. The challenge of the game and being skilled in the game did not affect learning directly through the increased engagement a strong predictor of learning outcomes. For the design of educational games, the results suggested that the challenge of a game should be able to keep up with the learners growing abilities and learning in order to endorse continued learning in game-based learning environments.
Video games are part and parcel of children's and adolescent lives. In the United States, about $97 \%$ of them playing at least one hour per day [28]. A lot of research has been carried out about video gaming although the majority are centered on the negative effects of gaming. Most young male children living alone are addicted to video games and have poor mental health [29]. However, the authors outlined some factors which would provide insight into the field of video game addiction which may help to provide supervision as to how one can identify people that are in risk of becoming addicted gamers. The basic question of whether or not "video game addiction" should be qualified as a mental disorder as many aspects of Internet Gaming Disorder theoretically remain contentious among researchers and clinicians [30].

The value of research aimed at the effects of gaming on negative impacts has been recognized [28]. However, the authors encouraged looking at the benefits as being important because the nature of such games has changed radically in the last decade, becoming progressively complex, diverse, realistic and social in nature.

In their findings, they summarized the results on positive effects of playing videogames focusing on four (4) main domains: cognitive, motivational, emotional and social. By incorporating understandings from developmental, positive and social psychology as well as media psychology, they proposed some candidate mechanisms by which playing video games may substitute real word psychosocial benefits.

The aim of providing strong enough evidence and theoretical rationale to inspire new programs of research on the largely unknown mental health benefits of gaming which in the end they called intervention researchers and practitioners to test the positive uses of video games which they suggest several favorable guidelines for doing so.

Also, the use of video games should be seen in a more balanced perspective not just in the negative dimension but also in the positive light [31].

An empirical study which focused on some selected private secondary and Tertiary schools in Ota [32]. In their study, they utilized both primary and secondary data by visiting the targeted schools' websites in order to get qualitative data on their e-learning experiences as well as their understanding on the usage. They also, granted interview to some staff and students by administering questionnaires so as to have direct contact with them and to obtain information on their experiences on e-learning. This method of survey gave the scholars the opportunity of obtaining "First hand" information from the strategic actors in the field. They examined the impact of e-learning in aiding academic performance using regression analysis based on testable hypothesis to achieve the study objective. The result of their analysis provided evidence on the meaningful impact of e-learning in assisting academics, self-development, upgrading learning process and noticed high performance in their academics.

However, they recommended that the management of schools should make more efforts in providing more elearning facilities in their schools and that students be 
inspired to make proper use of the facilities by giving them elearning related assignments and projects.

To understand and find the relationship between the academic performance of students and usage of mobile phones and to discover whether mobile phones are avenues of distractions to students, [33] embarked on a study. Information for the work was gathered using structured questionnaires which were administered to 45 students to get their individual view. In addition, 15 extensive interviews were done concurrently to in order to determine a full knowledge of students with the data gathered from the study. From findings, they discovered that students are influenced negatively to a great extent by the mobile phone; probably their attention is focused on chatting, music and lots more while abandoning academic activities to suffer.

From their discovery also, they gathered that the use of the mobile phone is overwhelming among students which are the leading cause of poor academic performance among students.

In another study by [34], he examined the awareness of the use of the phone for educational purpose by secondary school students. 250 senior secondary school students were carefully chosen from 4 public high schools in Ilesa Metropolis of Osun State, Nigeria. A self-developed questionnaire was divided into two sections with sixteen items on each section based on the research topic. Three (3) research questions were generated and answered. The result showed that majority of the respondents were aware of the educational use of mobile phones although, the frequency of the use for learning purpose was not encouraging. However, there was no significant relationship between the students' level of awareness and their use of the mobile phone for learning. Their study further encouraged that complete ban should not be placed on the use of mobile phones within the school environment by secondary school students but curriculum planners should incorporate the use of the mobile phone as a tool for learning while correct measures are put in place to guide the usage of phones within the school environment.

With the rapid innovation in Mobile technologies, the need to embrace mobile learning has become more important [35]. In their study, they revealed that the ease to use and access these mobile devices have made them more substantial than ever. The scope of their findings gained the importance of the need for mobile learning and meeting the new conditions.

They reviewed that using mobile environment gives learners the opportunity to access information anytime and anywhere and the range of size and features of these devices have recently been greatly used to enhance their effectiveness in the learning environment. In their study, they projected that Augmented Reality will develop and increase the proficiency of mobile learning and it could be made very common educational institutions. They reiterated that to get the benefit of mobile devices is to own one. On how to get these devices easily, they suggested that the devices can be provided through institutions and companies. Finally, in their conclusion, they stated that for years, researches have been carried out on e-learning, distant learning and mobile learning and results showed that mobile phones have sustained learning, increased the interaction and contributed to the persistence in learning. However, such researches always have conclusions that point to the fact that these devices on their own are never enough for learning but the manner in which they are used.

Many hopes have been placed in Information and Information Technologies (ICTs) as a viable solution to the challenge of delivering quality education in developing countries, specifically in rural and remote areas [36].

In their investigation, they reviewed the proof of the role of mobile phones-facilitated m-learning in contributing to better-quality educational outcomes in Asia by exploring the results of six (6) m-learning pilot projects that took place in Thailand, Philippines, India, Mongolia, and Bangladesh. Their study further examines the extent to which the use of mobile phones helped improved educational outcomes in two specific ways: in improving access to education and in promoting new learning. The result of the study indicated that while there was important evidence of mobile simplifying increased access, much less evidence existed on how mobiles promote new learning and the absence of a process of collecting primary data for this study meant that, in some cases, the data resulting from the projects reviewed did not always relate to the research question of the study.

To examine teachers' beliefs concerning the effects of using mobile devices by students and to determine if the beliefs differ according to the demographic characteristics and Internet use purposes, [37] revised a demographic information questionnaire using the scale established by [38] with validity and reliability studies and utilized 200 teachers. In whole, the scale had three dimensions (with a total of 15 items). Nine (9) items for the social effects, three (3) for psychological effects, and 3 for learning-related effects.

Based on the results of the study, teachers believed that students are affected by mobile devices on all three dimensions of the scale; social, psychological and learning dimensions. The most remarkable finding of the finding was related to the learning dimension of the beliefs concerning mobile devices scale. In every Internet usage drive examined, it was determined that the teachers' beliefs concerning the "learning" dimension were always more positive than those that do not use the Internet for any given purpose.

Educational systems are thus looking to e-learning programs to help address the challenges such as poor infrastructure, lack of teacher and learning materials and poorly prepared students [39]. Integrating technology into this context could be powerful methods to partially address the shortfalls of poor infrastructure, lack of teacher and learning material and poorly prepared students. The concerned authors examined the effect of a mobile city game called frequency 1550 developed by The Waag Society to help first-year secondary school students to playfully obtain historic knowledge of Medieval Amsterdam. They investigated students' commitment in the game, historical knowledge and motivation for History in general. A quasiexperiment was used on 458 students from twenty (20) classes from five (5) schools. Students in 10 of the classes 
played the mobile history game whereas the pupils in the other 10 classes received regular project-based lesson series. The end result showed that those students who played the game gained significantly more knowledge above those students who received the regular project-based instruction.

More so, after a careful review of related literature by different scholars, most of the authors supported that mobile educational games are beneficial to the students because it is motivating and also provides a fun way to learn. Investigations were carried out by some scholars in obtaining responses either from teachers alone or only students while others used data from sources such as meta-analysis, internet research, and revision of other authors' questionnaires. Other researchers proposed mobile educational games whose models had complexity in the development of the software. Also, it was apparent that some intellectuals are more inclined to investigate the negative aspects of the use of mobile devices while others are absorbed with considering the positive aspects of such mobile devices, especially their contributions to learning in the present day.

Our research, therefore, investigates the level of awareness, usage and intellectual influences of mobile educational games to secondary school students in Nigeria it promises to fill the gaps observed in some of the reviewed literature by obtaining valid responses directly from both key actors students and teacher in education using a questionnaire as a research tool.

\section{Methodology}

This research gathered data through questionnaire and case study. It was conducted in 2017. A questionnaire based on the objectives of the study was administered to 171 students and 52 teachers using a random sample out of the total number of 300 students and 60 Teachers of the school. The sample size was selected using Slovin's formula which is $n=N /(1+\mathrm{Ne} 2)$ where $n=$ Number of Samples, $N=$ Total population and $e=$
Error tolerance of calculating sample size [40].

A total of 168 and 52 usable questionnaires were returned by students and teachers respectively for a response rate of $97 \%$ and $100 \%$ respectively. The data were analyzed using descriptive statistics and the results are presented below.

\section{Results/Analysis of Data}

Currently, in Nigeria, a few mobile educational games have begun to spring up. An example of such games is the 'Who Wants to be a Millionaire Nigeria mobile App' launched in April 2016 [41]. The aim of the app is for playing, learning and winning. Its features include:

i. Players have to subscribe for it at N50 for MTN subscribers.

ii. 45 additional questions are purchased by SMS, pin, Credit/Debit cards

iii. Players play and make their way up the virtual money 10million naira Tree using the 3 available life-lines.

iv. Players get a chance of getting on the Hot seat by subscribing and playing in order to be on the leader board. The top players win money on weekly and monthly bases and score attained while playing the game can be shared with friends on social media.

\subsection{Availability of Android Phones}

The results showed that the availability of Android phones to respondents was not common. Some students and staff responded that they own Android phones while some indicated they do not own Android phones. Only thirty-one $(18 \%)$ of the students own android phones while one hundred and thirty-seven $(82 \%)$ of the students responded that they do not own Android phones. For Teachers, seventeen (33\%) responded they own android phones while thirty-five (67\%) do not own Android phones.

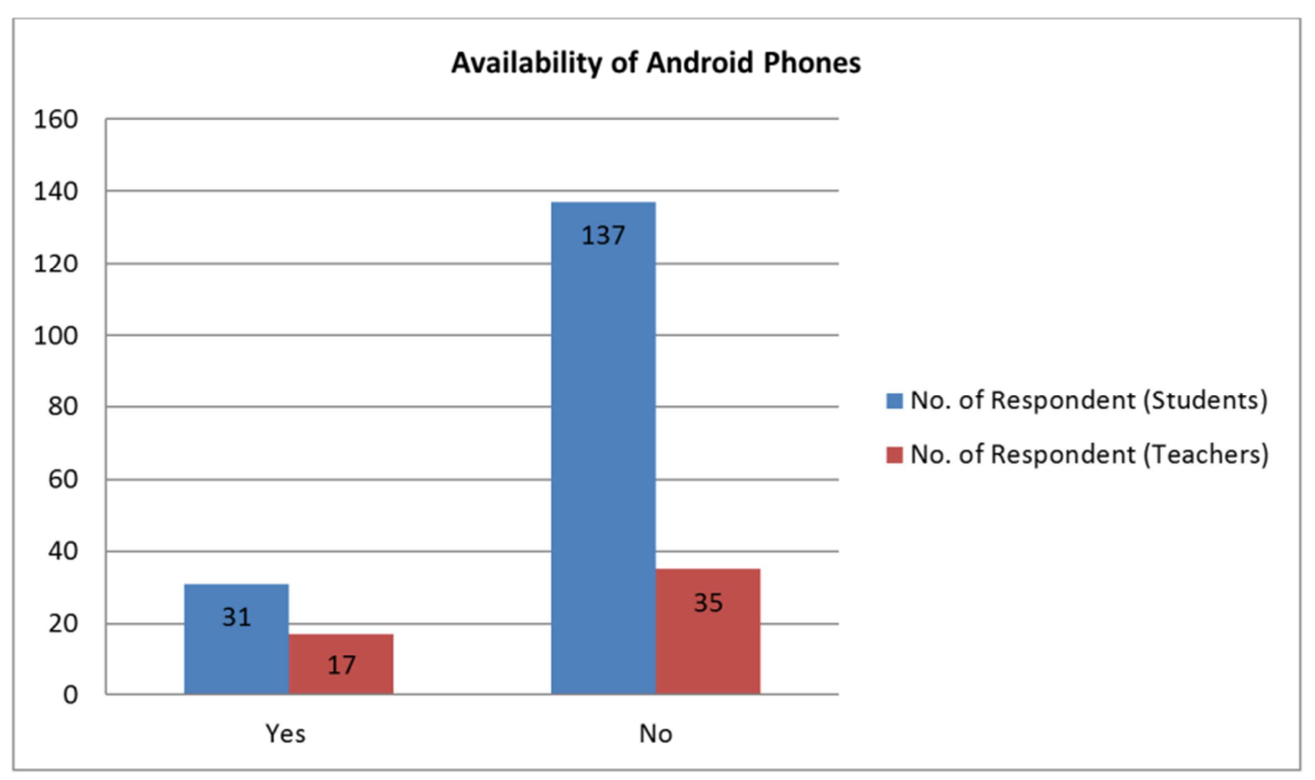

Figure 1. Availability of android phones. 


\subsection{Awareness of Mobile Educational Games by Students and Teachers}

There is much significant difference in the number of students that are aware of mobile educational games than those who are not aware of. Sixty-one (36\%) of respondents from students category indicated that they are aware of the existence of mobile educational games while one hundred and seven (64\%) indicated that they are not aware of the existence of mobile educational games. From Teachers category, there is no far difference in the number that indicated they are aware of the existence of android mobile educational games and those who are not aware. Twentyseven $(52 \%)$ responded that they are aware of existing mobile educational games and twenty-five (48\%) responded that they are not aware of mobile educational games as shown in Figure 2.

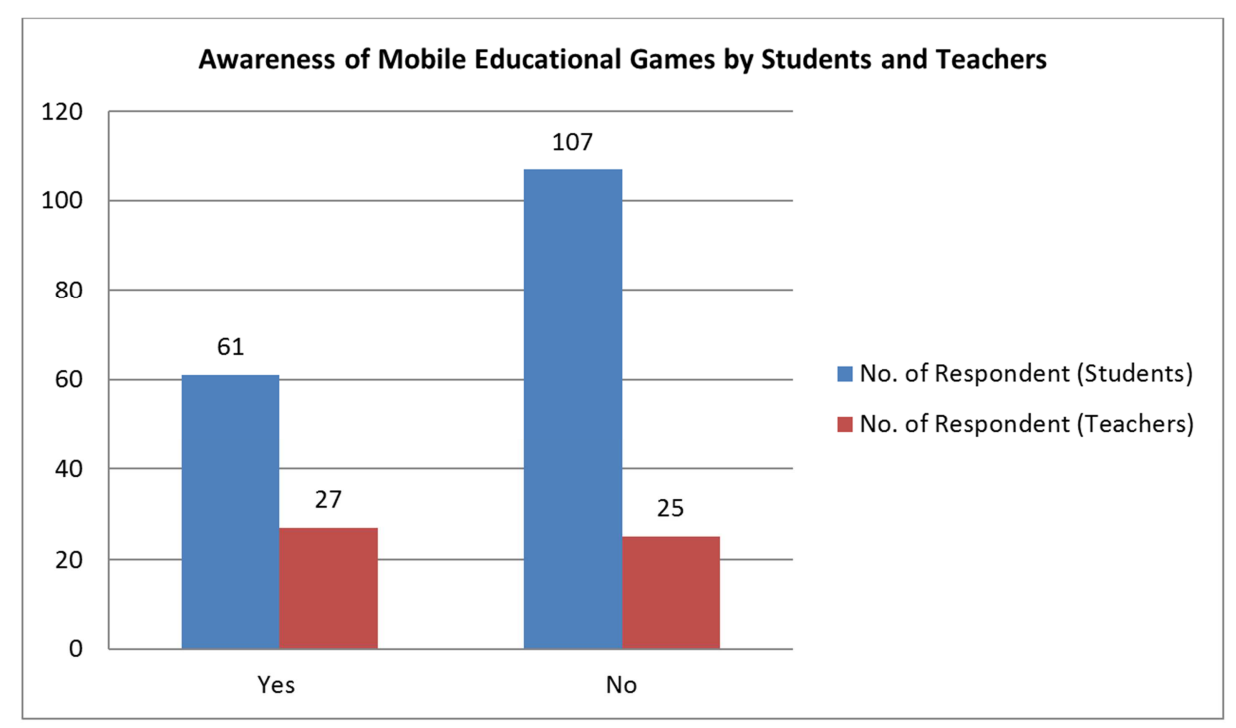

Figure 2. Awareness of Mobile Educational Games by Students and Teachers.

\subsection{Use of Mobile Educational Games by Students and Teachers}

There is a significant difference in the number of students that have used mobile educational games and those that have not. Seventy-two respondents $(43 \%)$ indicated that they have used mobile educational games and ninety-six respondents $(57 \%)$ indicated that they have not used mobile educational games. From Teachers, there is no much difference in the number of those that have used mobile educational games only a few responded that they have not used mobile educational games. Twenty four respondents (46\%) showed that they have used mobile educational games while twentyeight respondents $(54 \%)$ indicated that they have never used mobile education games as shown in Figure 3.

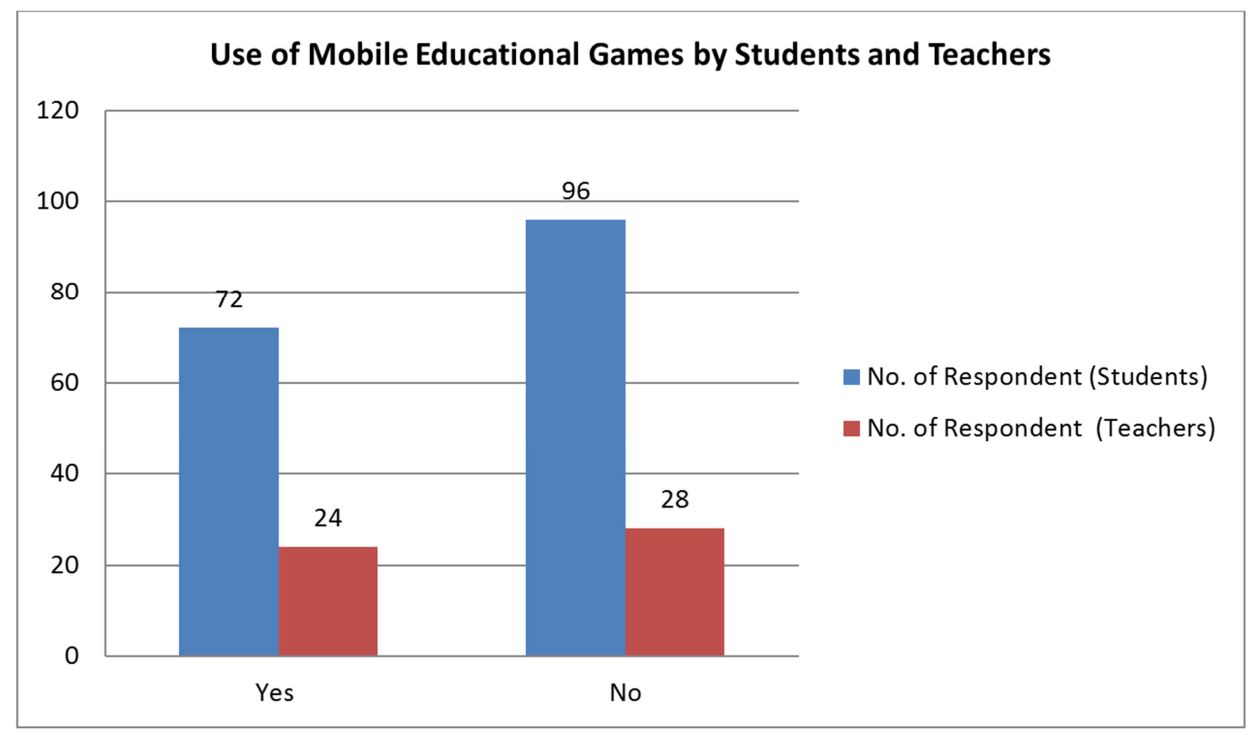

Figure 3. Use of Mobile Educational Games by Students and Teachers. 


\subsection{Type of Mobile Educational Games Used Most by Students and Teachers}

There is a significant difference in the number of students that have used the different types of existing mobile educational games. Seventy-two respondents $(43 \%)$ indicated that they have used the Who wants to be a Millionaire game, seventeen respondents $(10 \%)$ shows they have not used the Who wants to be a Millionaire Quiz game, five respondents (3\%) specified they have used other existing mobile educational games not mentioned in this study and seventy- four respondents $(44 \%)$ indicated that they have never used mobile educational games. While from Teachers, eighteen respondents $(34.6 \%)$ responded that they have used the Who wants to be a Millionaire Game, five respondents $(9.6 \%)$ showed they have used the Millionaire Quiz, two respondents $(3.8 \%)$ indicated they have used other mobile educational game not specified in the questionnaire and twenty-seven respondents $(52 \%)$ indicated they have never used any existing mobile educational game all shown in figure 4.

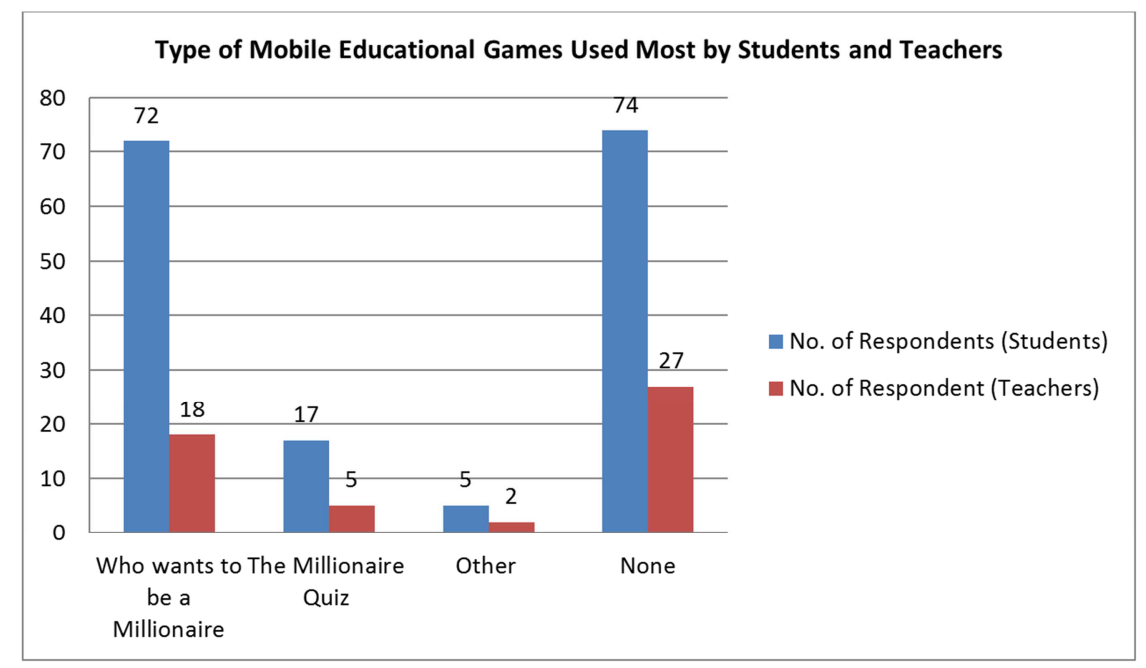

Figure 4. Type of Mobile Educational Games Used Most by Students and Teachers.

\subsection{Ascertain if Mobile Educational Games Used Is Based on Secondary School Subjects}

There is a disparity in the percentage of students and teachers that answered the questions on whether mobile educational games are based on subjects taught in schools. From students, ninety-five respondents (57\%) indicated that the existing games are based on subjects taught in secondary schools while seventy-three respondents $(43 \%)$ replied that the existing mobile educational games are not based on secondary school subjects. While from Teachers, a few numbers of twelve respondents $(23 \%)$ indicated that existing mobile educational games are based on secondary school subjects and majority number of forty respondents (77\%) responded that existing mobile educational games are not based on subjects taught in secondary schools as shown in figure 5 .

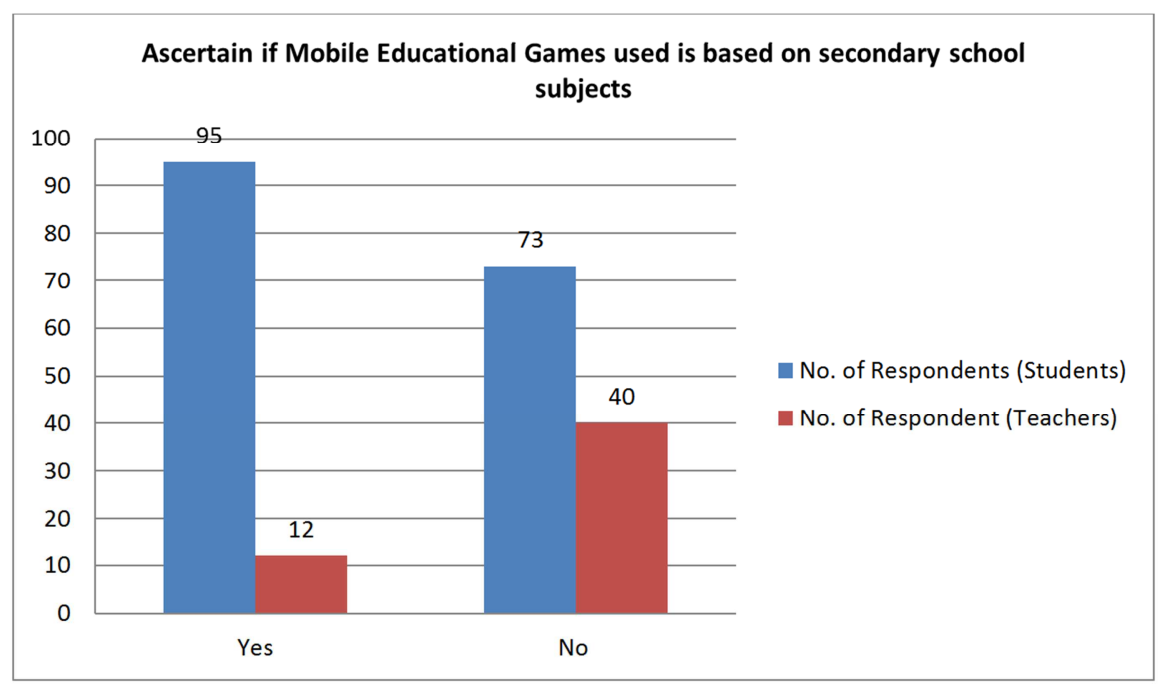

Figure 5. Ascertain if Mobile Educational Games used is based on secondary school subjects. 


\subsection{Mobile Educational Games Assistance in Learning and Teaching}

We have different responses from students and teachers on whether the existing mobile educational games aid in learning and teaching is not the same on both sides of Students and Teachers. From Students, ninety-one respondents $(54 \%)$ specified that the existing games assist them in learning while seventy-seven respondents (46\%) indicated that such game (s) do not assist them academically. From teachers' responses, twenty-two respondents (42\%) indicated that the mobile educational games assist in teaching while thirty respondents (58\%) showed that existing mobile educational games do not assist them in teaching the students as shown in figure 6 .

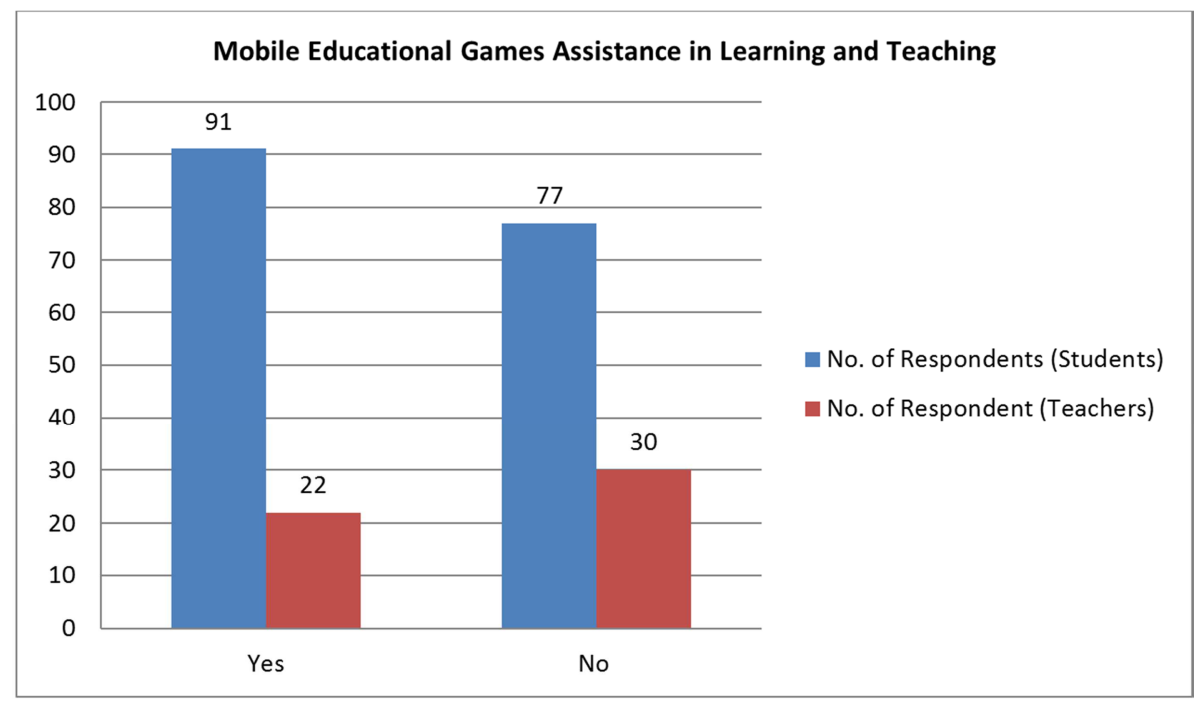

Figure 6. Mobile Educational Games Assistance in Learning and Teaching.

\subsection{Degree of the Helpfulness of the Existing Mobile Educational Games in Learning and Teaching}

The result below shows responses to discover how relevant existing mobile educational games are to students and teachers. From students, seventy-six respondents (45\%) indicated that the existing mobile educational games are very helpful to them in their academics, thirty-four respondents $(20 \%)$ indicated that they are helpful, ten respondents $(6 \%)$ were neutral (neither helpful nor not helpful) and forty-eight respondents
$(29 \%)$ specified that the existing games are not helpful to their academics. On the side of teachers, a fewer number of eighteen respondents $(35 \%)$ indicated that existing mobile educational games are very helpful, eight respondents $(15 \%)$ of the teachers responded that the games are helpful, five respondents $(10 \%)$ were neutral about the helpfulness of such games while the greatest portion of twenty-one respondents $(40 \%)$ indicated that existing mobile educational games are not helpful in teaching students as shown in figure 7.

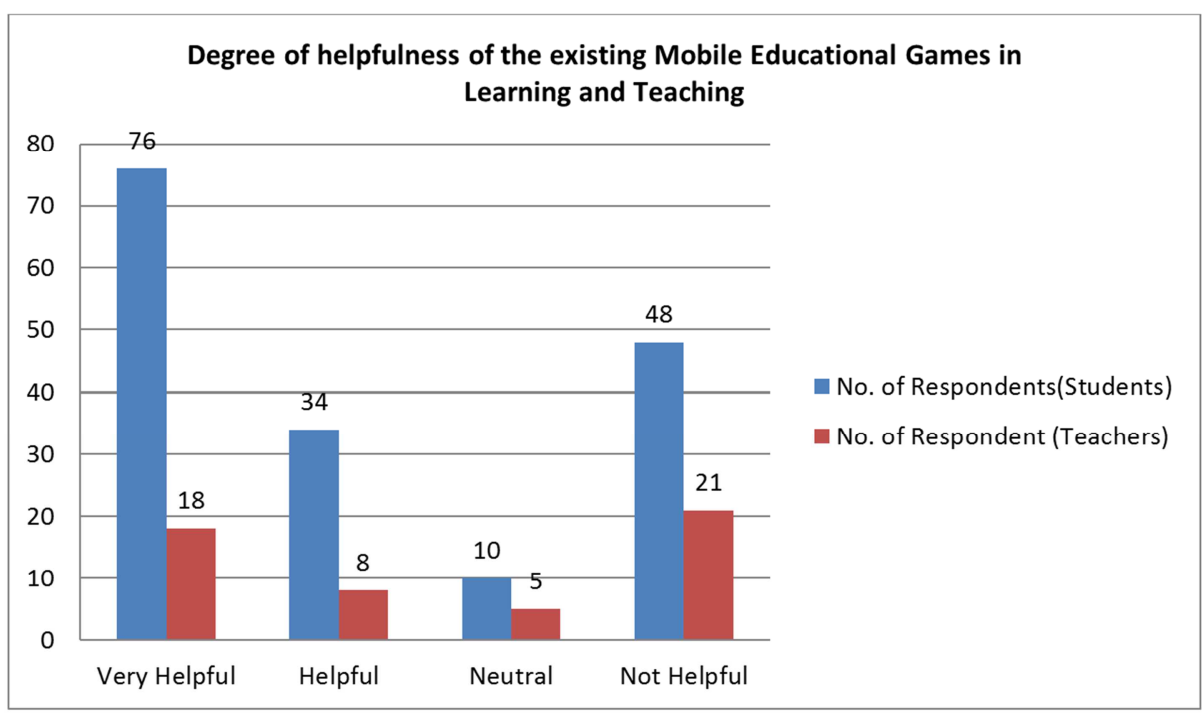

Figure 7. Degree of the helpfulness of the existing Mobile Educational Games in Learning and Teaching. 


\subsection{School Subjects Represented Most by the Game (s)}

The result below shows responses to the school subjects that have questions represented most. From students, twenty six respondents $(15 \%)$ chose English Language, seventeen respondents $(10 \%)$ indicated Mathematics, one respondent (1\%) selected Social Studies, twenty-seven respondents (16\%) chose Health Education, eight respondents $(5 \%)$ chose Civic Education, thirty respondents (18\%) chose Computer Science, ten respondents $(6 \%)$ chose History, four respondents $(2 \%)$ indicated Literature-in-English and forty-five respondents
(27\%) chose the None option. On the part of Teachers, nine respondents (17\%) went for English, two respondents (4\%) went for Mathematics, one respondent (2\%) went for Social Studies, eleven respondents (21\%) indicated Health Education, two respondents (4\%) chose Civic Education, four respondents (8\%) indicated Computer Science, seven respondents $(13 \%)$ chose History, three respondents $(6 \%)$ indicated Literature-inEnglish and a huge number of thirteen respondents (25\%) went for the None option.

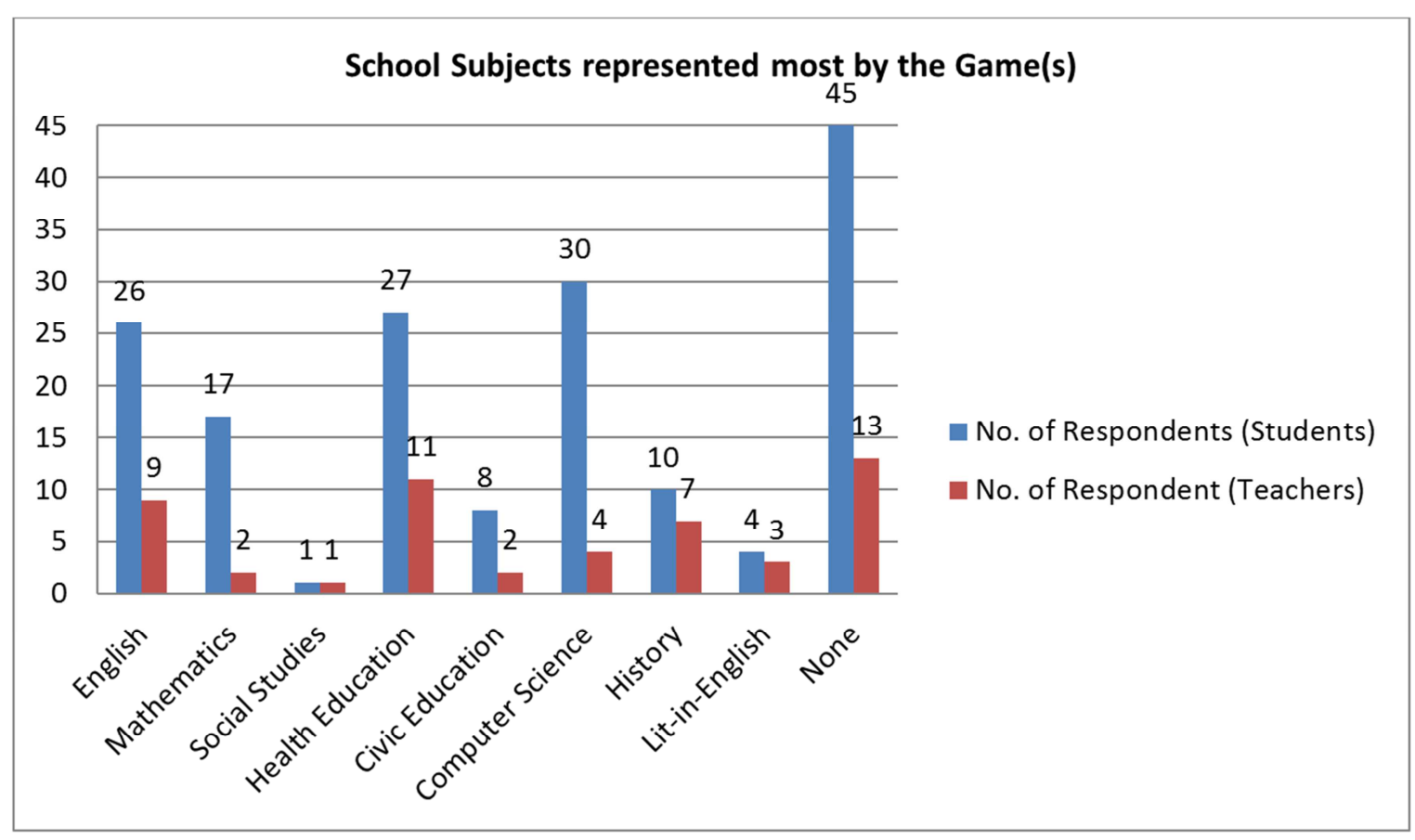

Figure 8. School Subjects represented most by the Game (s).

\section{Discussion}

According to the survey, most students do not have android phones. Similarly, a good number of teachers do own android phones. A considerable number of students and a greater part of the teachers responded they are aware of the existence of mobile educational games. For the usage of mobile education games, a good number of students and teachers responded they are not only aware of such games but also have used some of them. The commonly used type is the Who wants to be a Millionaire Nigeria apps, follow by the Millionaire Quiz game and Learn Grammar (mentioned by a respondent).

The result of the survey also shows that mobile educational games generally assist more students than teachers in learning and teaching respectively. To ascertain the degree of relevance of such games, a greater number of students indicated that the use of such games are very helpful while a greater percentage of teachers indicated that the use of mobile educational games is not helpful to teaching.

Furthermore, in the area of which school subjects are represented in most existing mobile educational games, a larger part of both students and teachers indicated the None option which implies that none of the subjects taught in secondary school is fully represented in existing mobile educational games. We, therefore, recommend that intended mobile educational games should be designed to accommodate subjects taught in secondary schools in Nigeria. Also, students and teachers should be effectively exposed to those mobile educational games.

\section{Conclusion}

This study investigated the awareness, accessibility, effectiveness, and level of satisfaction in the utilization of mobile educational outdoor learning game among staff and students of Government Girls' Secondary School Makurdi, Nigeria. A quantitative research approach was adopted. A sample of 169 students and 52 teachers were used. Questionnaires were administered to them. Our results show that: $64 \%$ of students and $52 \%$ of teachers were aware of mobile educational games. $43 \%$ of students and $46 \%$ of 
teachers used mobile educational games. $54 \%$ of students and $42 \%$ of teachers responded that Mobile educational games assist learning and teaching. $45 \%$ of students and $35 \%$ of teachers responded that existing mobile educational games are very helpful in assisting learning and teaching. $57 \%$ of students and $23 \%$ of teachers indicated that existing mobile educational games are not based on secondary school subjects. The study recommended that selected questions for such games should be based on the Nigerian secondaryschool curriculum; also, students and teachers should be effectively exposed to these mobile educational games so as to enhance the quality of education in the secondary school sector in Nigeria.

\section{Acknowledgements}

This research received no specific grant from any funding agency in the public, commercial, or not-for-profit sectors.

\section{References}

[1] National Information and communication Technology Policy, 2012.

[2] Obahiagbon, K and Otabor, JO (2014). Information and Communication Technology (ICT) Key Tool for Enhancing Teaching and Learning in Nigeria: A Study of Two Tertiary Institutions in Benin Metropolis. American Journal of Educational Research, 2 (12), pp 1257-1259.

[3] Rula AL-Azawi, Fatma Al-Faliti and Mazin Al-Blushi (2016) Educational Gamification Vs. Game-Based Learning: Comparative Study. International Journal of Innovation, Management and Technology, Vol 7, No. 4.

[4] Kinzie, MB and Joseph, R. D (2008) Gender differences in game activity preferences of middle school children: Implications for Educational games design". Educational Tech. Research Dev 56: 643-663.

[5] Randel, J. M., Morris, B. A., Wetzel, C. D., \& Whitehill, B. V. (1992). The effectiveness of games for educational purposes: A review of recent research. Simulation \& Gaming, 23 (3), 261-276.

[6] Kirriemuir J and Mcfarlane A (2004) Literature Review in Games and Learning. A NESTA Futurelab Research report report 8 .

[7] Lavin-Mera, Torrente J, Moreno-Ger P, and FernandezManjon B (2008) Development of educational videogames in m-learning contexts, In IEEE Conference on Digital Game and Intelligent Toy-enhanced learning (DIGITEL 2008). Banff, Canada. IEEE Computer Society.

[8] Amr Kannan (2012) "Learning through Games: Essential Features of an Educational Game" Instructional Design, Development and Evaluation - Dissertations. Paper 56.

[9] Mine Okur and Erdal Aygenc (2018) EURASIA Journal of Mathematics, Science and Technology Education, vol 14 number 3: 977-985.

[10] Victor Samuel Zirawaga, Adeleye Idowu Olusanya, Tinovimbanashe Maduku (2017) Gaming in Education: Using
Games as a Support Tool to Teach History. Journal of Education and Practice www.iiste.org Vol. 8, No. 15, 2017.

[11] Petkov, M., \& Rogers, G. (2011). Using Gaming to Motivate Today's Technology-Dependent Students. Virginia Tech Libraries, 48 (17), 9. Retrieved from: http://scholar.lib.vt.edu/ejournals/JSTE/v48n1/pdf/petkov.pdf.

[12] Ryan L. Schaaf and Keri Engel (nd) "Learning with digital games". Available at: https://cdn2.hubspot.net/hubfs/2751142/Aqua/Reading_Learni ngWithDigitalGames.pdf?t=1535637800290.

[13] Aldrich, C (2005) Learning by Doing: A Comprehensive Guide to Simulations, Computer Games and Pedagogy in elearning and other Educational Experiences. San Francisco, CA: Pfeiffer.

[14] Lepper, MR and Cordova, DI. A desire to be taught: Instructional consequences of intrinsic motivation. Motivation and Emotion, vol. 16: 187-208, 1992.

[15] Malone T (1981) Toward a Theory of Intrinsically Motivating Instruction. Cognitive Science, vol 5: 333-369.

[16] Prensky, M (2011) Digital Game-Based Learning. New York McGraw-Hill.

[17] Games4Ed (2015) Why Games are Important to Education. Available at http://www.games4ed.org/who-we-are/why-gamesare-important-to-education/ (accessed 22 November 2017).

[18] Michel, 2016 Michel, H. (2016). Characterizing serious games implementation's strategies: Is higher education the new playground of serious games? Institute of Electrical and Electronics Engineers (IEEE).

[19] Lavin - Mera P, Torrente J, Moreno-Ger P and FernandezManjon B (2009) Mobile Game Development for Multiple Devices in Education, In the International Conference on Mobile and Computer Aided Learning.

[20] Leetian CRN, Estuar ER., and Syson B (2013) Designing Mobile Educational Games on Voter's Education: A Tale of Three Engines, International Journal of e-education, eBusiness, e-Management and e-Learning. 3 (5): 357-364.

[21] Yao-Ting Sung, Kuo-En Chang, Tzu -Chien Liu (2016) The effects of integrating mobile devices with teaching and learning on students' learning performance. A meta-analysis and research synthesis. Elsevier International Journal for Computer \& Education. Vol 94 page 252-275.

[22] Milczynski KA. Literature Review: Effectiveness of Gaming in the Classroom. British Journal of Education Technology 41, 256-270. Available at https://msu.edu/ milczyn1/artifacts/LITERATUREREVIEW_ KAREN_MILCZYNSKI.pdf (Accessed on 22 November 2017).

[23] Pannese, L., and Carlesi M. (2007) "Games and Learning come together to maximise effectiveness: The challenge of bridging the gap". British Journal of $\mid$ Educational Technology. Vol 38 No 3 page 438-454.

[24] McLester, S. (2005). Game Plan: Technology and Learning. 26 (3), 18-20, 22, 24, 26.

[25] Mehdipour Y and Zerehkafi H (2013) Mobile Learning for Education: Benefits and Challenges. International Journal of Computational Engineering Research Vol 03, Issue 6. 
[26] Kraleva R, Kralev V and Kostadionova D (2016). A Conceptual Design of Mobile Learning Applications for Preschool Children. International Journal of Computer Science and Information Security Vol. 14, No.

[27] Hamari J, Shernoff DJ, Rowe E, Coller B, Asbell-Clark J, and Edwards T (2015) Challenging games help Students Learn: An empirical study on engagement, flow and immersion in game-based learning. Computers in Human Behaviour 54 (2016) 170-179.

[28] Granic I, Lobel A, and Engels R C. M. E (2014). The Benefit of Playing Video Games. https://www.ncbi.nlm.nih.gov/pubmed/24295515.

[29] Wittek, C. T., Finserås, T. R., Pallesen, S. et al. (2016). Prevalence and Predictors of Video Game Addiction: A Study Based on a National Representative Sample of Gamers. Int $J$ Ment Health Addiction 14: 672. https://doi.org/10.1007/s11469-015-9592-8.

[30] Bean, A. M., Nielsen, R. K. L., van Rooij, A. J., and Ferguson, C. J. (2017, July 6). Video Game Addiction: The Push To Pathologize Video Games. Professional Psychology: Research and Practice. Advance online publication. http://dx.doi.org/10.1037/pro0000150. Retrieved from: https://www.researchgate.net/publication/317335670_Video_ Game_Addiction_The_Push_To_Pathologize_Video_Games [accessed Jun 04 2018].

[31] Prot, S., Anderson, C. A., Gentile, D. A., Brown, S. C., and Swing, E. L. (2014). The positive and negative effects of video game play. In A. Jordan \& D. Romer (Eds.). Media and the Well-Being of Children and Adolescents (109-128). New York: Oxford University Press.

[32] Fayomi O, Ayo C and Okorie LU (2015) The Impacts of Elearning in Facilitating Academic Performance among Private Secondary Schools and Tertiary Institutions in Ota, Ogun State Nigeria.

[33] Soyemi J, Oloruntoba SA and Okafor B (2015) Analysis of Mobile Phone Impact on Students Academic Performance in Tertiary Institution. International Journal of Emerging Technology and Advanced Engineering, Volume 5, Issue 1.

[34] Jubril B. F. (2017) Secondary School students' awareness and use of mobile Phones for academic purpose. Educational Journal of the University of Patra UNESCO Chair 4 (1) p. 8393, ISSN: 2241-9152.

[35] Idris G and Bunyamin A (2013) Need for Mobile Learning: Technologies and Opportunities. $13^{\text {th }}$ International Technology Conference.

[36] John-Harmen V, Ahmed TR and Laurent (2010) Using Mobile Phones to Improve Educational Outcomes: An Analysis of Evidence from Asia. The International Review of Research in Open and Distance Learning.

[37] Gonca K. C. (2015) How Mobile Devices Affect Students According To Teachers' Beliefs, Journal of International Education Research - Fourth QuPrensarter, Volume 11, Number 4.

[38] Yelkin Diker Coskun and Gonca Kizilaya Cumaoglu (2013) Scale of teachers' belief on the effect of the use of mobile devices on students, Procedia - Social and Behavioral Sciences 106, pp 2299-2306.

[39] Huizenga J, Admiraal W, Akkerman S and ten Dam G (2009)
Mobile game-based learning in Secondary education: engagement, motivation and learning in a mobile city game. Journal of Computer Assisted Learning.

[40] Statistics How To (2017) Available at http://www.statisticshowto.com/how-to-use-slovins- formula/.

[41] Who Wants to Be a Millionaire Nigeria Apps (2016) Available at http://www.pulse.ng/gist/who-wants-to-be-a-millionaireintroducing-the-app-for-nigeria-id4917988.html.

\section{Biography}

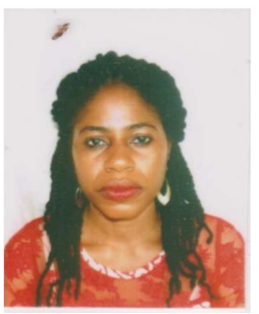

Yugh Sandra Mlumun B.Sc, M.Sc, MNIM, MNIWIT, MNCS, Hails from Gwer West Local Government Area of Benue State, She is a Software Developer/Web Designer and Graphic Designer, Currently she works with Federal Medical Centre Makurdi as a Senior Programme Analyst in Planning, Research and Statistics Unit.

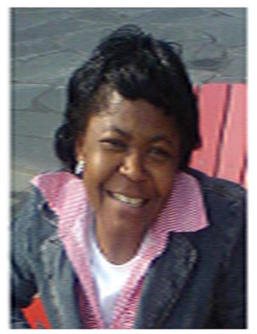

Deborah Uzoamaka Ebem Dr. Ir. Engr. (Mrs) Deborah Uzoamaka Ebem is a Senior Lecturer in the department of Computer Science, University of Nigeria, Nsukka. She was one of the pioneer students of the Department of Computer Science and Engineering at the then Anambra State University of Technology (ASUTECH), Nigeria. Her researches areas are in ICT development and deployment, Perceptual Measurement of Speech Quality and Speech Intelligibility, development of Igbo Hearing in Noise Test (IHINT), Artificial Intelligence, Data Science, Parallel Computing and Parallel Algorithm, Mobile Outdoor games, Network Architecture and Services, Data Communication Networks, cybercrime, grid computing and Enterprise Resource Planning (ERP).

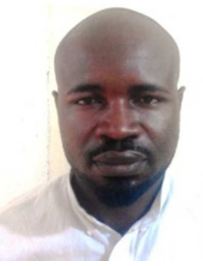

Onyianta John Chiedozie is from Enugu State, Nigeria. He received the B. Sc. and M. Sc. degree in Computer Science from the University of Nigeria, Nsukka respectively. With a specialization in artificial intelligence, his current research interests include the use of artificial intelligence techniques to improve personalized and collaborative learning. He has worked in partnership with other researchers in some other areas of computer science ranging from modelling to design and implementation.

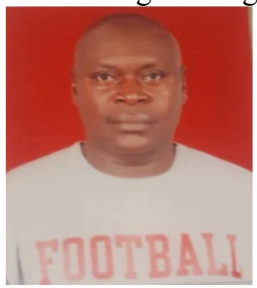

Musa Ibrahim Umar is from Taraba State, Nigeria and has obtained his M. Sc degree from the Department of Computer Science, University of Nigeria Nsukka. He is currently working with the Department of Extension and Management, College of Agriculture, Jalingo, Taraba State, Nigeria. 
Yugh Sandra Mlumun et al.: Intellectual Impact of Mobile Educational Games on Secondary School Education in Nigeria: Case Study of Government Girls' College Makurdi

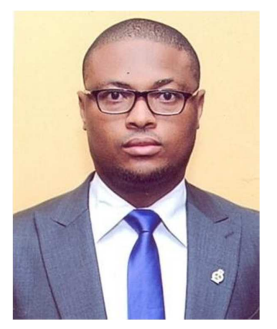

Arinze Uchechukwu Christian holds B. Sc and M. Sc degrees and is currently a Nuclear Security, Nuclear Knowledge Management Expert and an ICT Engineer with the Nigerian Nuclear Regulatory Authority (NNRA). His researches are in developing algorithms for improved congestion control in wireless telecommunication and data communication networks such as: local area networks (LANs), wide area networks (WANs), wireless local area networks (WLANs), global system for mobile communication (GSM), enhanced data rate for GSM evolution (EDGE), long-term evolution (LTE). Others include: data centre costing models; numerical algorithms, optimization, cyber security, software engineering and database and Hypermedia systems respectively. 